\title{
Stereotactic Body Radiation Therapy for Liver Tumors: Current Status and Perspectives
}

\author{
HIROSHI DOI ${ }^{1,2,3}$, NAOHITO BEPPU ${ }^{4}$, KAZUHIRO KITAJIMA $^{2}$ and KOZO KURIBAYASHI ${ }^{5}$ \\ ${ }^{1}$ Department of Radiation Oncology, Meiwa Cancer Clinic, Nishinomiya, Japan; \\ ${ }^{2}$ Department of Radiology, Hyogo College of Medicine, Nishinomiya, Japan; \\ ${ }^{3}$ Department of Radiation Oncology, Kindai University Faculty of Medicine, Osaka-Sayama, Japan; \\ ${ }^{4}$ Department of Surgery, Meiwa Hospital, Nishinomiya, Japan; \\ ${ }^{5}$ Division of Respiratory Medicine, Department of Internal Medicine, \\ Hyogo College of Medicine, Nishinomiya, Japan
}

\begin{abstract}
Surgical resection is the standard therapy for solitary primary or metastatic liver tumors. However, liver tumors are often unresectable at diagnosis and hepatectomy is invasive. Local therapies, such as radiofrequency ablation, are used instead, which can be challenging. Recent advances in modern radiotherapy, including stereotactic body radiation therapy (SBRT), have increased the use of radiotherapy as a curative modality. SBRT delivers ablative high doses of irradiation in small volumes. SBRT for liver tumors provided local control with potential survival benefits in patients with inoperable status. However, the following issues remain: primary vs. metastatic liver cancers; SBRTrelated toxicity and prevention; pathological features of liver cancers; and potential SBRT strategies. We summarized a literature review to summarize the effectiveness of SBRT and patient tolerance and present the current status and future perspective of SBRT for liver tumors. SBRT is a potential game changer for multimodal therapy.
\end{abstract}

Surgical resection is the standard therapy for liver malignancies, including primary and metastatic liver tumors (1). Other local therapies, such as radiofrequency ablation

This article is freely accessible online.

Correspondence to: Dr. Hiroshi Doi, Department of Radiation Oncology, Meiwa Cancer Clinic 3-39, Agenaruocho, Nishinomiya, Hyogo, 663-8186 Japan. Tel: +81 798814552, Fax: +81 798814562, e-mail: h-doi@med.kindai.ac.jp

Key Words: Radiotherapy, stereotactic body radiation therapy, stereotactic ablative radiotherapy, hepatocellular carcinoma, metastatic liver tumor, review.
(RFA), percutaneous ethanol injection therapy, and transarterial chemoembolization (TACE), are used as alternatives in medically-inoperable patients with hepatocellular carcinoma (HCC) and metastatic liver tumors (1-6). However, radical treatment for liver tumors can be challenging due to poor liver function, tumor location and progression, and anatomical barriers $(2,5)$. Furthermore, preservation of residual liver function is required, as liver tumors have high recurrence potential $(5,6)$.

High doses of radiation are required for $\mathrm{HCC}$ that would sometimes exceed the levels tolerated by the background liver. Radiotherapy has also been used for palliative care in liver tumors (7-9). Modern radiotherapies, including stereotactic body radiation therapy (SBRT), intensity-modulated radiotherapy (IMRT), and particle therapies, have recently attracted increasing attention as therapeutic modalities for various malignancies and have dramatically increased the use of radiation therapy as a curative modality (10-26).

Several studies using SBRT for liver tumors have reported high tumor response and local control rates $(2,3)$. However, certain issues regarding the current use of SBRT for liver tumors need to be addressed. These include the differences between primary and metastatic liver cancers, SBRT-related toxicity and prevention, the pathological features of liver cancers, and the clinical application of novel radiobiologybased SBRT strategies, such as a combination of SBRT with immunotherapy.

We conducted a review of the literature to summarize the effectiveness and patient tolerance of this new treatment modality, to summarize the differences between primary and metastatic liver tumors, to report the probable treatmentrelated toxicities and their prevention, and to describe recent significant updates on microinvasion, the biological behavior of SBRT, and combined therapy with immune therapy. 


\section{Stereotactic Body Radiation Therapy (SBRT)}

The major feature that distinguishes SBRT from conventional radiation treatment is the delivery of large doses of radiation in a few fractions, which results in a high biologically effective dose (BED). The use of a high precision technique is critical to deliver a high dose of radiation to the target and keep rapid fall-off doses away from the target, thereby achieving maximum treatment efficacy with minimal toxicity to normal tissues (27).

The use of SBRT for extracranial tumors was developed at the Swedish Karolinska University by Blomgren and colleagues (28). SBRT is now widely accepted as a treatment option for lung and liver tumors characterized by their small size and limited numbers (29). The present status of SBRT for liver tumors is documented below.

\section{SBRT for Primary Liver Cancers}

The Barcelona Clinic Liver Cancer staging system is now widely accepted in clinical practice over the other staging systems (1). Orthotopic liver transplantation offers the best cure for liver cancer, even though the chances of transplantation are limited due to the lack of sufficient liver donors (30). Therefore, it is envisaged that radiotherapy would play the role of a radical therapy in the populations that require orthotopic liver transplantation as a cure rather than a bridging therapy $(31,32)$. Moreover, recent reports indicated that SBRT was as effective as TACE and RFA $(33,34)$. In a previous series, SBRT provided 1-, 2-, and 3-year local control rates of 56-100\%, 53-95\%, and 51-92\%, and 1-, 2-, and 3-year survival rates of $32-100 \%, 55-100 \%$, and $21-82 \%$ for HCC, respectively (11-19).

There are only a limited number of reports of the use of SBRT for cholangiocellular carcinoma (CCC). In a previous series, SBRT provided a 1-year local control rate of 50-100\% (20-21). Kopek et al. reported a median local control time and an overall survival time of 6.7 and 10.6 months, respectively, in 27 CCC patients who received SBRT (21). Over a median follow-up period of 5.4 years, the local control rate was $81.5 \%$, after exclusion of intrahepatic recurrence (21).

SBRT can generally achieve excellent local control of primary liver tumors, even if the patient was not a good candidate for surgery or RFA.

\section{SBRT for Metastatic Liver Tumors}

Oligometastases have recently been recognized as a state in which the patient shows distant relapse in only a limited number of regions, and a possible benefit from local treatment for oligometastases has been reported for various malignancies $(4,35)$. Surgical resection is the standard treatment option for colorectal oligometastases and good outcomes have been reported $(3,6)$. Furthermore, reports indicate that other alternative local interventions provide excellent local control $(4,5)$. In these populations, the general condition of patients can deteriorate with disease progression and adverse events after treatment; therefore, minimally invasive treatments are preferred.

In recent years, high tumor control rates post-SBRT have dramatically changed the role of radiotherapy from palliative care to radical intent. SBRT can provide 1-, and 2-year local control rates of $62-100 \%$, and $45-100 \%$ for liver metastases, respectively, and is therefore a potential therapeutic candidate for the treatment of oligometastases $(17,21-26)$.

\section{Prescription Doses of SBRT for Liver Tumors}

A dose-response relationship has been reported for conventional fractionated and stereotactic radiotherapy, although the best prescription dose of radiotherapy for HCC remains undecided $(36,37)$. Furthermore, the use of tumor control probability (TCP) models has been reported in terms of BED using the linear-quadratic (LQ) model with an assumed $\alpha / \beta$ ratio of $10 \mathrm{~Gy}$ for the tumor $\left(\mathrm{BED}_{10}\right)$ (38). Lausch et al. estimated that a $90 \%$ probability of 6-month local control could be achievable by administration of 2 Gy per fraction with an equivalent dose of $84 \mathrm{~Gy}\left(\mathrm{BED}_{10}=100.8 \mathrm{~Gy}\right)(7)$. Jang et al. estimated that $51.1 \mathrm{~Gy}$ in 3 fractions (BED10=138.1 Gy) were necessary to achieve a $90 \%$ probability of 2-year local control (39). Sanuki et al. and Takeda et al. estimated a $>90 \%$ probability of 3-year local control with 40 Gy in 5 fractions $\left(\mathrm{BED}_{10}=72 \mathrm{~Gy}\right)$ that was intended to enclose the planning target volume (PTV) by the $80 \%$ isodose-line of the maximum dose $(15,16)$. Based on these data, we treated HCC with $>80$ Gy of $\mathrm{BED}_{10}$ designed to deliver $100 \%$ of the prescription dose to $95 \%$ of the PTV using intensitymodulated radiation therapy (IMRT) $(40,41)$. Notably, when there was no constraint on the PTV during planning, the maximum dose for PTV could be slightly escalated from the prescription doses (Figure 1).

For metastatic liver tumors, the prescription doses depend on the primary tumor; colorectal histology was a significant negative predictive factor $(42,43)$. In patients with colorectal cancer with a limited number of metastases, local control of metastatic lesions may be curative $(3,4,6)$. Chang et al. reported that $>117$ Gy $(e . g . \geq 48 \mathrm{~Gy}$ in 3 fractions $)$ would be required to achieve an estimated 1-year local control rate of $90 \%$ in a TCP model from a pooled analysis (24). Lausch et al. calculated 2 Gy per fraction with equivalent doses of $95 \mathrm{~Gy}\left(\mathrm{BED}_{10} \geq 114 \mathrm{~Gy}\right)$ to achieve a $90 \%$ probability of 6-month local control (7). The need for dose escalation for liver or pulmonary metastases with colorectal histology has recently reported (25). Using a radiosensitivity index that reflected the expressive gene types, Ahmed et al. reported 

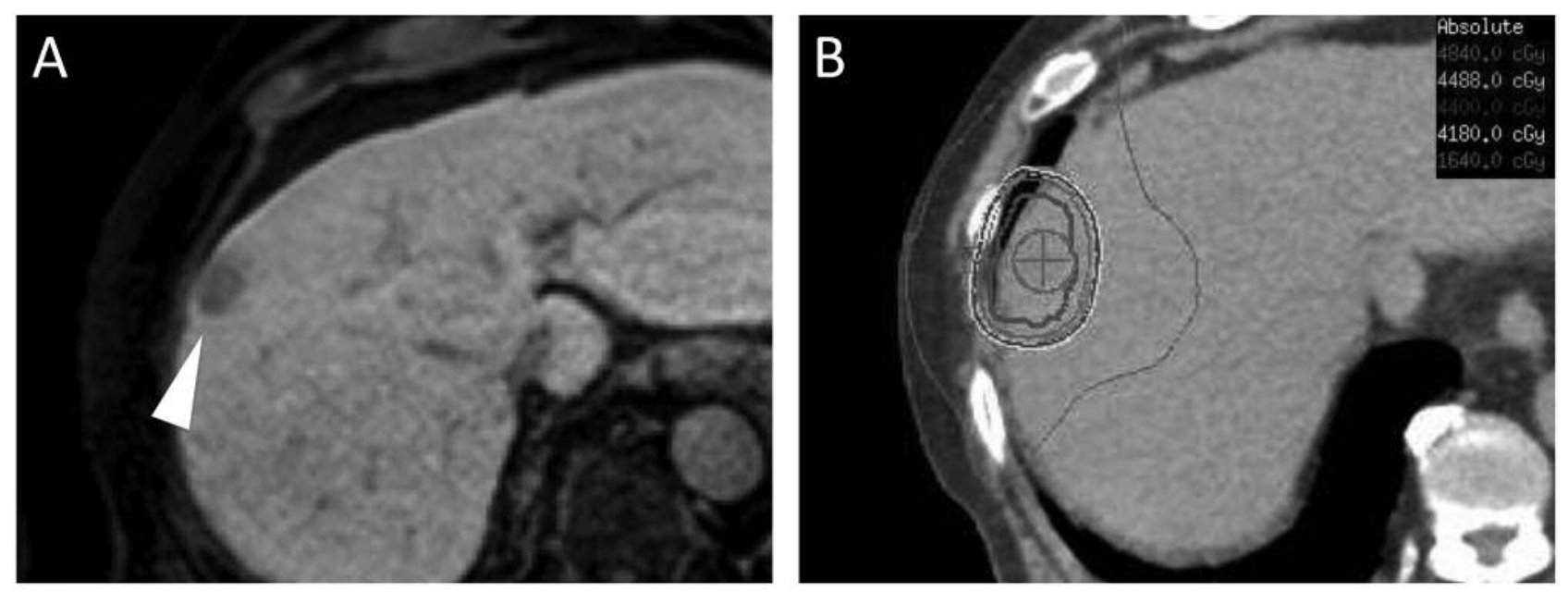

Figure 1. An 81-year-old man with HCC. HCC of $24 \mathrm{~mm}$ in diameter was present just beneath the diaphragm (A, Gd-EOB-DTPA enhanced-MRI, arrowhead). The tumor was not easily detectable in ultrasound scans and percutaneous intervention was difficult. SBRT of 44 Gy in 4 fractions was applied as a $D 95$ prescription (B, treatment plan). The maximum dose of PTV was escalated to $128.3 \%$ of the prescription doses. The patient was included in our prospective study (approval no. 28-16). HCC: Hepatocellular carcinoma; Gd-EOB-DTPA: gadolinium ethoxybenzyldiethylenetriaminepentaacetic acid; MRI: magnetic resonance imaging; SBRT: stereotactic body radiation therapy; BED: biologically effective dose; D95: prescribed dose to cover 95\% of the PTV; PTV: planning target volume.

that liver metastases from colorectal cancer were radioresistant compared with other histological cancer types $(43$, 44). We hypothesized that metastatic liver tumors had different biological backgrounds and responses to irradiation, and that significant factors included tumor size, metastatic site, and primary histology.

For HCC and colorectal liver metastases $<3 \mathrm{~cm}$, we suggest prescription doses of greater than $\mathrm{BED}_{10}$ of 80 and 100 , respectively. Dose escalation and modification of the treatment schedule is required for metastatic tumors $\geq 3 \mathrm{~cm}$ $(18,23,26)$.

\section{Adverse Events of SBRT for Liver Tumors}

Manifestations of liver SBRT toxicity include fatigue, damage to the liver, gastrointestinal tract, and biliary duct, cytopenia, dermatitis, and rib fractures (12-26). Adverse events of radiotherapy depend on the treatment site, and the irradiated doses and volume and are categorized into either acute or late, based on their time of onset (45). In liver SBRT, it is often difficult to clearly separate acute and late phases of toxicities because liver damage with serum aminotransferase elevation occur weeks or months after SBRT (10). We focus on the major cases of toxicity involving the liver, gastrointestinal tract, and central bile duct.

Hepatic toxicity. The most important dose-limiting factor of liver radiotherapy is liver damage, such as radiation-induced liver disease (RILD). RILD is classified into 2 different clinical conditions, classic and non-classic $\operatorname{RILD}(8,9)$.

In a retrospective analysis of SBRT involving $221 \mathrm{HCCs}$, Sanuki et al. reported a $1.1 \%$ occurrence rate of Grade 5 hepatic toxicity (15). There are differences in radiosensitivity between patients with normal and cirrhotic livers $(9,40)$. Moreover, Child-Pugh B, particularly scores $\geq 8$, was considered a significant risk factor for severe hepatic toxicity and a poor prognosis $(12,18)$. Culleton et al. reported that survival among patients with a Child-Pugh score $\geq 8$ was significantly shorter than among patients with Child-Pugh 7 in a study involving $29 \mathrm{HCC}$ patients with Child-Pugh B or $\mathrm{C}$ who received SBRT (18). Furthermore, radiotherapy has the potential to reactivate hepatitis $\mathrm{B}$ virus and differentiating patients may be necessary (47).

As the liver is widely accepted as a parallel organ, a part of it can receive a high dose of irradiation as long as the functions as a whole organ are preserved (48-50). After SBRT, focal dysfunction was noted in the irradiated background liver. A liver volume $>700 \mathrm{ml}$ has been used as a dose constraint when the dose administered was less than 15 and 17 Gy in 3 fractions $(13,51,52)$. Using magnetic resonance imaging (MRI), Sanuki et al. have shown that the threshold dose of focal liver dysfunction was $30 \mathrm{~Gy}$ and 25 Gy in 5 fractions in patients with Child-Pugh A and B, respectively (53). Doi et al. reported that focal liver dysfunction can occur at $40 \mathrm{~Gy}$ and $70 \mathrm{~Gy}$ of BED2 in the cirrhotic and normal liver, respectively, at the minimum dose 


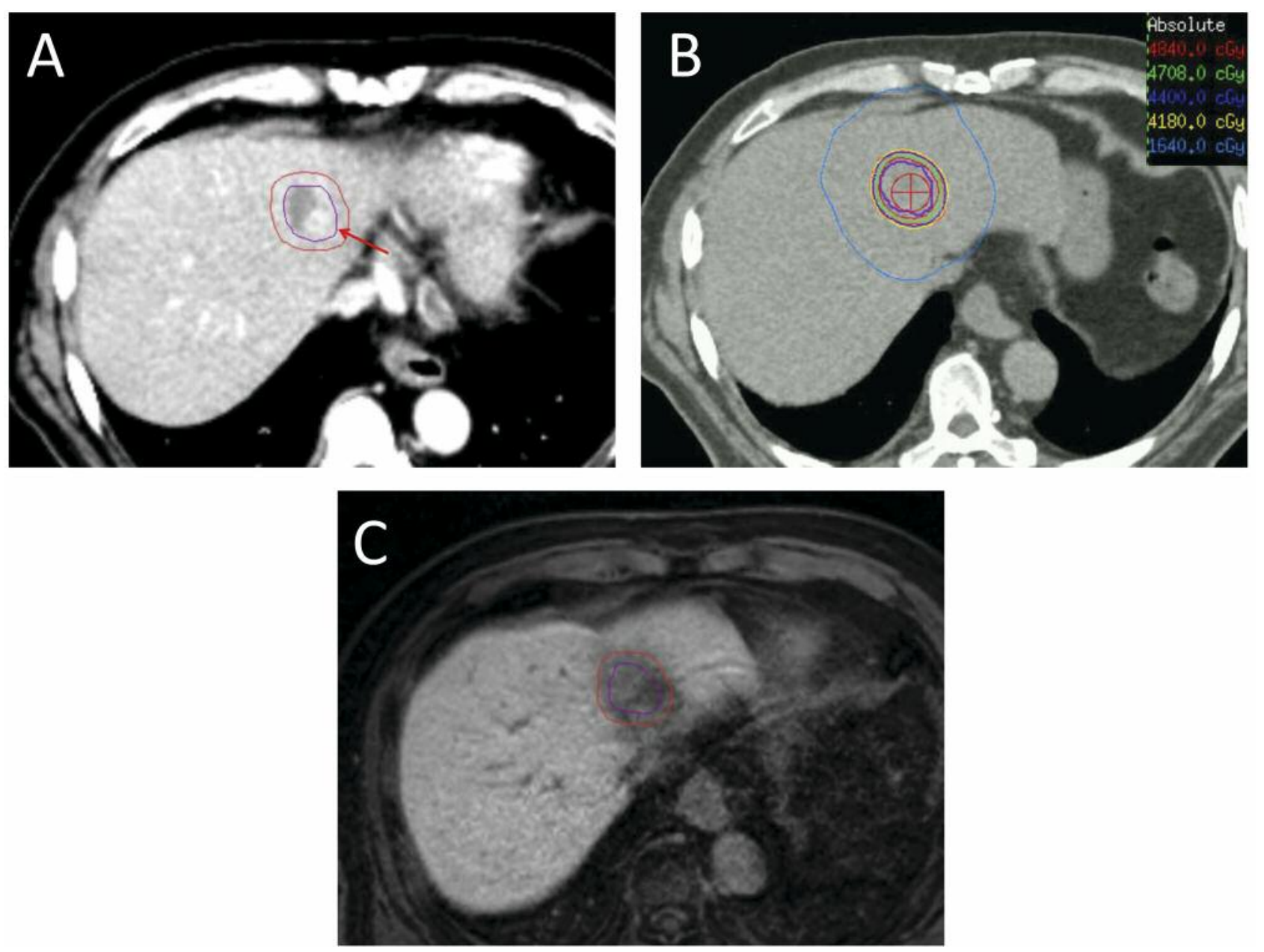

Figure 2. A 65-year-old man with HCC. HCC was found with hypervascularity just dorsal to the low-density area in which RFA was performed (A, contrast-enhanced CT, arrow). Purple and orange lines indicate the ITV and PTV, respectively. SBRT of 44 Gy in 4 fractions was applied (B). Blue line indicates the potential hepatocyte dysfunction area $\left(B E D_{2}=50 \mathrm{~Gy}\right)$. A low intensity area was found in the follow-up Gd-EOB-DTPA enhancedMRI 3 months after SBRT (C). MRI was fused with planning CT, with use of a fiducial marker (Gold Anchor ${ }^{T M}$; Naslund Medical AB, Huddinge, Sweden), as a landmark. The patient was included in our prospective study (approval no. 28-16). HCC: Hepatocellular carcinoma; RFA: radiofrequency ablation; CT: computed tomography; ITV: internal target volume; PTV: planning target volume; SBRT: stereotactic body radiation therapy; BED: biologically effective dose; D95: prescribed dose to cover 95\% of the PTV; Gd-EOB-DTPA: gadolinium ethoxybenzyldiethylenetriaminepentaacetic acid; MRI: magnetic resonance imaging.

suggested for SBRT for liver tumors $(40,41)$. Intrahepatic recurrence often occurs after radical treatment for both HCC and metastatic liver tumors, and such tumors have a chance to receive second radical treatment $(5,6)$. Therefore, prediction of the volume of liver dysfunction is essential in order to spare the residual liver volume (Figure 2).

The doses that the liver receives have a strong positive relationship with the irradiated target volume $(41,54)$. Particle therapy can reduce the liver volume that receives low to intermediate doses, resulting in the reduction of mean liver doses (55). A relevant clinical consideration is that particle therapy can benefit relatively large tumors, such as those $>3 \mathrm{~cm}$ (particularly those $>5 \mathrm{~cm}$ ) and patients with poor liver function, which are limiting factors for SBRT (56).

Gastrointestinal injury. Gastrointestinal injuries, including bleeding, ulcers, and perforations have been described and the incidence of symptomatic gastrointestinal toxicities was less than $10 \%$ in majority of the previous reports.

Hoyer et al. reported 1 case of colonic perforation and 2 duodenal ulcers in patients in whose intestine received $\geq 30$ Gy in 3 fractions from 64 patients receiving liver SBRT (57). Yamashita et al. reported that $6.9 \%$ of 130 patients receiving liver SBRT developed gastrointestinal toxicity of 
Grade 2 or above (22). Kang et al. reported that $6.4 \%$ and $4.3 \%$ of patients experienced Grade 3 gastrointestinal toxicity and Grade 4 gastric ulcer perforation, respectively, in 47 HCC patients (15). In addition, Barney et al. reported that the combination of SBRT and a vascular endothelial growth factor inhibitor increased the risk of Grade 3 or greater gastrointestinal toxicities (58).

Kopek et al. recommended V21Gy $\leq 1 \mathrm{cc}$ for the duodenum in abdominal SBRT, based on dose-volume data (29). Bae et al. concluded that the Dmax was the best dosimetric predictor for severe gastroduodenal toxicity and the Dmax of 35 Gy and 38 Gy in 3 fractions was associated with a probability of $5 \%$ and $10 \%$ severe gastroduodenal toxicity, respectively (59). Kavanagh et al. recommended that the volume of stomach receiving $>22.5$ Gy should be minimized and ideally limited to less than $5 \mathrm{ml}$, with a maximum point dose of $<30 \mathrm{~Gy}$ for three-fraction SBRT (60). Sanuki et al. suggested that severe toxicities could be avoided when the distance between the target and the bowel is $>2 \mathrm{~cm}$ (61).

Central hepatobiliary tract toxicity. Eriguchi et al. documented asymptomatic bile duct stenosis in $2 / 50$ patients receiving $>20 \mathrm{~Gy}$ in 5 fractions to the central liver, and concluded that SBRT for liver tumors in the hepatic hilum was feasible with minimal biliary toxicity (62).

Osmundson et al. reported the following: 23 patients (24.0\%), including 14 of 20 patients with CCC, developed hepatobiliary toxicity $\geq$ Grade 2 in 96 patients with liver tumors who received SBRT (63). Furthermore, CCC, biliary stent, $\mathrm{V}_{\mathrm{BED} 10} 72 \geq 21 \mathrm{cc}, \mathrm{V}_{\mathrm{BED} 10} 66 \geq 24 \mathrm{cc}$, and DmeanBED 10 $\geq 14$ Gy to the central hepatobiliary tract were associated with hepatobiliary toxicity (63). Therefore, there can be potential dose constraints due to central hepatobiliary tract toxicity.

The same groups analyzed resected surgical specimens and reported radiation-induced pathological changes in the bile duct 25 months after SBRT (64). They showed fibrotic changes in different tissues in the hepatic hilum, involving the bile duct, porta hepatis, portal vein, and adjacent peritoneum. The bile duct was thickened not only in the area adjacent to the tumor but also on the contralateral side that was uninvolved by the tumor.

The same group, in a study of 130 patients who received liver SBRT, has recently suggested $\mathrm{V}_{\mathrm{BED} 10} 40<37 \mathrm{ml}$ and $\mathrm{V}_{\mathrm{BED} 10} 30<45 \mathrm{ml}$ as dose-volume constraints in SBRT for primary liver tumors (65). The anatomical structures in the hepatic hilum make radical treatment for liver tumors more challenging; therefore, SBRT can be a feasible treatment option.

\section{Current Issues and Future Perspective of Liver SBRT}

Current unsolved questions remain regarding the pathological features of liver cancers and potential SBRT strategies, including radiobiology-based SBRT and SBRT combined with immunotherapy. We discussed these issues above.

Current status of biology-based SBRT. Brown et al. reported that endothelial cell damage and vascular damage can cause secondary cancer cell apoptosis and fractionated radiotherapy has an increased antitumor effect, based on the impact of reoxygenation (66). Shibamoto et al. concluded that a 72hour break period from SBRT could promote reoxygenation that enhances the indirect effects of ionizing radiation, resulting in improved tumor control (67). There is no prospective clinical trial directly comparing the 2 SBRT schedules, with or without a break.

Larger tumors are usually a SBRT exclusion criterion, although the response to SBRT in cases of relatively small tumors remains unclear $(16,22,24,34,41)$.

Biological assessment could identify potential factors that improve treatment outcomes, such as escalated doses, treatment schedule with a break, combined therapy with ideal chemotherapy, patient selection, and use of particle therapies $(26,54,55)$.

Microscopic extension of liver tumors in terms of clinical tumor volume margin. Clinical tumor volume (CTV) is frequently equal to the gross tumor volume (GTV) in SBRT (68). It is still poorly understood whether CTV margins are necessary to include both gross and microscopic disease. We document below the possible CTV margins reported regarding liver tumors.

Approximately $95 \%$ of patients with HCC who could be candidates for SBRT had microscopic extension of $\leq 2$ to $3.5 \mathrm{~mm}(69,70)$.

Bi et al. devised a scoring system based on the combination of these factors, including the tumor boundary, tumor markers, and liver transaminases, and suggested that an increase in the GTV by approximately 5 to $8 \mathrm{~mm}$ was necessary to cover microscopic invasion with $\geq 95 \%$ probability (71).

Qian et al. suggested that 3-8.5 mm CTV margins were necessary in order to cover microscopic invasions in 139 resected specimens of colorectal liver metastases (72). We previously reported that a larger margin for the GTV tended to improve local control and survival outcomes and, to the best of our knowledge, this is the first report establishing the requirement of CTV margins in clinical data (26). Further clinical trials are required to assess the need for CTV margins.

Perspective of immuno-SBRT. This response can lead to systemic induction of antitumor immunity, causing tumor shrinkage in distant sites from the irradiated areas, known as the abscopal effect. The abscopal effect is induced by irradiation via an indirect effect on T lymphocytes (73). The abscopal effect is well established, although SBRT combined with anti-cytotoxic T-lymphocyte-associated protein-4 
(CTLA-4) therapy, ipilimumab, resulted in unexpected clinical complete responses in distant sites from the irradiated areas; this occurred in a range of malignancies, such as metastatic melanoma and metastatic lung cancer (74-76).

Immune checkpoint inhibitors represent a significant breakthrough and a promising strategy in recent cancer treatments. Synergistic effects of immuno-radiotherapy have recently been reported in clinical and pre-clinical studies, including the increased possibility of the abscopal effect, which may lead to a significant change in treatment strategies for metastatic cancers (74-78).

The optimal treatment schedule for a combination of radiotherapy and immunotherapy is still not understood even today. Wild et al. found that hypofractionation could minimize the toxic effects on circulating lymphocytes in SBRT for pancreatic cancer (79). Young et al. reported enhanced efficacy of immune-radiotherapy administered concurrently with radiotherapy compared with sequential administration (80). Bang et al. found that larger doses of radiotherapy and short breaks between immunotherapy and radiotherapy increased the rate of toxicity (81).

In recent reports on immune-radiotherapy, radiotherapy was largely delivered using SBRT or a short course of palliative radiation, although the optimal method of radiotherapy delivery remains unknown. By expanding its application range from small tumors to metastases, SBRT appears to have good potential to achieve newer objectives in systematic disease.

\section{Limitations}

Our review has a number of limitations. First, there are only a small number of randomized trials examining the use of SBRT in HCC with no report on metastatic liver tumors. Second, as the chances of patients receiving surgical resection after SBRT are limited, the biological characteristics of each tumor that received SBRT are not well defined. Liver tumors include a range of tumors, such as $\mathrm{HCC}, \mathrm{CCC}$, and metastatic tumors from different primary sites. These diversities make the role of liver SBRT more complicated and challenging. Additional prospective studies involving large sample sizes are required to consolidate the evidence on SBRT, assess the benefit of escalated doses of SBRT for each tumor type in terms of local control and survival, define superiority or inferiority compared with that of local treatment modalities, and thus develop a standardized treatment protocol.

\section{Conclusion}

For liver tumors, SBRT is safe and effective, with excellent local control achieved. Therefore, novel strategies should be developed based on new knowledge of biological responses to radiation therapy. State-of-the-art liver SBRT remains a pioneering strategy and a possible game changer in multimodal therapy.

\section{Acknowledgements}

The Authors would like to thank Editage (www.editage.com) for English language editing and Publication Support.

\section{References}

1 Bruix J, Reig M and Sherman M: Evidence-based diagnosis, staging, and treatment of patients with hepatocellular carcinoma. Gastroenterology 150: 835-853, 2016

2 de Baere T, Tselikas L, Yevich S, Boige V, Deschamps F, Ducreux M, Goere D, Nguyen F and Malka D: The role of image-guided therapy in the management of colorectal cancer metastatic disease. Eur J Cancer 75: 231-242, 2017.

3 Scheele J, Stang R, Altendorf-Hofmann A and Paul M: Resection of colorectal liver metastases. World J Surg 19: 59-71, 1995.

4 Abitabile P, Hartl U, Lange J and Maurer CA: Radiofrequency ablation permits an effective treatment for colorectal liver metastasis. Eur J Surg Oncol 33: 67-71, 2007.

5 Tateishi R, Shiina S, Yoshida H, Teratani T, Obi S, Yamashiki N, Yoshida H, Akamatsu M, Kawabe T and Omata M: Prediction of recurrence of hepatocellular carcinoma after curative ablation using three tumor markers. Hepatology 44: 1518-1527, 2006.

6 de Jong MC, Pulitano C, Ribero D, Strub J, Mentha G, Schulick RD, Choti MA, Aldrighetti L, Capussotti L and Pawlik TM: Rates and patterns of recurrence following curative intent surgery for colorectal liver metastasis: An international multi-institutional analysis of 1669 patients. Ann Surg 250: 440-448, 2009.

7 Lausch A, Sinclair K, Lock M, Fisher B, Jensen N, Gaede S, Chen $\mathrm{J}$ and Wong E: Determination and comparison of radiotherapy dose responses for hepatocellular carcinoma and metastatic colorectal liver tumours. Br J Radiol 86: 20130147, 2013.

8 Emami B, Lyman J, Brown A, Coia L, Goitein M, Munzenrider JE, Shank B, Solin LJ and Wesson M: Tolerance of normal tissue to therapeutic irradiation. Int J Radiat Oncol Biol Phys 21: 109-122, 1991

9 Pan CC, Kavanagh BD, Dawson LA, Li XA, Das SK, Miften M and Ten Haken RK: Radiation-associated liver injury. Int $\mathbf{J}$ Radiat Oncol Biol Phys 76: S94-100, 2010.

10 Sakurai H, Ishikawa $\mathrm{H}$ and Okumura T: Proton beam therapy in Japan: current and future status. Jpn J Clin Oncol 46: 885-892, 2016.

11 Sanuki N, Takeda A and Kunieda E: Role of stereotactic body radiation therapy for hepatocellular carcinoma. World $\mathbf{J}$ Gastroenterol 20: 3100-3111, 2014.

12 Andolino DL, Johnson CS, Maluccio M, Kwo P, Tector AJ, Zook J, Johnstone PA and Cardenes HR: Stereotactic body radiotherapy for primary hepatocellular carcinoma. Int J Radiat Oncol Biol Phys 81: e447-e453, 2011.

13 Kang JK, Kim MS, Cho CK, Yang KM, Yoo HJ, Kim JH, Bae SH, Jung DH, Kim KB, Lee DH, Han CJ, Kim J, Park SC and Kim YH: Stereotactic body radiation therapy for inoperable hepatocellular carcinoma as a local salvage treatment after incomplete transarterial chemoembolization. Cancer 118: 54245431, 2012. 
14 Bae SH, Kim MS, Cho CK, Kim KB, Lee DH, Han CJ, Park SC and Kim YH: Feasibility and efficacy of stereotactic ablative radiotherapy for Barcelona clinic liver cancer-C Stage hepatocellular carcinoma. J Korean Med Sci 28: 213-217, 2013.

15 Sanuki N, Takeda A, Oku Y, Mizuno T, Aoki Y, Eriguchi T, Iwabuchi $\mathrm{S}$ and Kunieda E: Stereotactic body radiotherapy for small hepatocellular carcinoma: a retrospective outcome analysis in 185 patients. Acta Oncol 53: 399-404, 2014.

16 Takeda A, Sanuki N, Eriguchi T, Kobayashi T, Iwabutchi S, Matsunaga K, Mizuno T, Yashiro K, Nisimura S and Kunieda E: Stereotactic ablative body radiotherapy for previously untreated solitary hepatocellular carcinoma. J Gastroenterol Hepatol 29: 372-379, 2014

17 Yamashita H, Onishi H, Matsumoto Y, Murakami N, Matsuo Y, Nomiya $\mathrm{T}$ and Nakagawa K; Japanese Radiological Society multi-institutional SBRT study group (JRS-SBRTSG): Local effect of stereotactic body radiotherapy for primary and metastatic liver tumors in 130 Japanese patients. Radiat Oncol 9: 112, 2014.

18 Culleton S, Jiang H, Haddad CR, Kim J, Brierley J, Brade A, Ringash $\mathrm{J}$ and Dawson LA: Outcomes following definitive stereotactic body radiotherapy for patients with Child-Pugh B or C hepatocellular carcinoma. Radiother Oncol 111: 412-417, 2014.

19 Wahl DR, Stenmark MH, Tao Y, Pollom EL, Caoili EM, Lawrence TS, Schipper MJ and Feng M: Outcomes after stereotactic body radiotherapy or radiofrequency ablation for hepatocellular carcinoma. J Clin Oncol 34: 452-459, 2016.

20 Tanguturi SK, Wo JY, Zhu AX, Dawson LA and Hong TS. Radiation therapy for liver tumors: ready for inclusion in guidelines? Oncologist 19: 868-879, 2014

21 Kopek N, Holt MI, Hansen AT and Høyer M: Stereotactic body radiotherapy for unresectable cholangiocarcinoma. Radiother Oncol 94: 47-52, 2010

22 Takeda A, Sanuki N and Kunieda E: Role of stereotactic body radiotherapy for oligometastasis from colorectal cancer. World J Gastroenterol 20: 4220-4229, 2014.

23 Rusthoven KE, Kavanagh BD, Cardenes H, Stieber VW, Burri SH, Feigenberg SJ, Chidel MA, Pugh TJ, Franklin W, Kane M, Gaspar LE and Schefter TE: Multi-institutional phase I/II trial of stereotactic body radiation therapy for liver metastases. J Clin Oncol 27: 1572-1578, 2009.

24 Chang DT, Swaminath A, Kozak M, Weintraub J, Koong AC, Kim J, Dinniwell R, Brierley J, Kavanagh BD, Dawson LA and Schefter TE: Stereotactic body radiotherapy for colorectal liver metastases: a pooled analysis. Cancer 117: 4060-4069, 2011.

25 Takeda A, Sanuki N, Tsurugai Y, Oku Y and Aoki Y: Stereotactic body radiotherapy for patients with oligometastases from colorectal cancer: risk-adapted dose prescription with a maximum dose of 83-100 Gy in five fractions. J Radiat Res 57: 400-405, 2016.

26 Doi H, Uemoto K, Suzuki O, Yamada K, Masai N, Tatsumi D, Shiomi $\mathrm{H}$ and Oh RJ: Effect of primary tumor location and tumor size on the response to radiotherapy for liver metastases from colorectal cancer. Oncol Lett 14: 453-460, 2017.

27 Benedict SH, Yenice KM, Followill D, Galvin JM, Hinson W, Kavanagh B, Keall P, Lovelock M, Meeks S, Papiez L, Purdie T, Sadagopan R, Schell MC, Salter B, Schlesinger DJ, Shiu AS, Solberg T, Song DY, Stieber V, Timmerman R, Tomé WA, Verellen D, Wang L and Yin FF: Stereotactic body radiation therapy: the report of AAPM Task Group 101. Med Phys 37: 4078-4101, 2010.

28 Blomgren H, Lax I, Näslund I and Svanström R: Stereotactic high dose fraction radiation therapy of extracranial tumors using an accelerator: clinical experience of the first thirty-one patients. Acta Oncol 34: 861-870, 1995.

29 Timmerman RD, Herman J and Cho LC: Emergence of stereotactic body radiation therapy and its impact on current and future clinical practice. J Clin Oncol 32: 2847-2854, 2014.

30 Soyama A, Eguchi S and Egawa H: Liver transplantation in Japan. Liver Transpl 22: 1401-1407, 2016.

31 Matsuo Y, Yoshida K, Nishimura H, Ejima Y, Miyawaki D, Uezono $\mathrm{H}$, Ishihara $\mathrm{T}$, Mayahara $\mathrm{H}$, Fukumoto $\mathrm{T}, \mathrm{Ku} \mathrm{Y}$, Yamaguchi M, Sugimoto K and Sasaki R: Efficacy of stereotactic body radiotherapy for hepatocellular carcinoma with portal vein tumor thrombosis/inferior vena cava tumor thrombosis: evaluation by comparison with conventional three-dimensional conformal radiotherapy. J Radiat Res 57: 512-523, 2016.

32 Xi M, Zhang L, Zhao L, Li QQ, Guo SP, Feng ZZ, Deng XW, Huang XY and Liu MZ: Effectiveness of stereotactic body radiotherapy for hepatocellular carcinoma with portal vein and/or inferior vena cava tumor thrombosis. PLoS One 8 : e63864, 2013.

33 Nugent FW, Qamar A, Stuart KE, Galuski K, Flacke S, Molgaard C, Gordon F, Iqbal S, Hunter KU, Hartnett E and Gunturu K: A randomized phase II study of individualized stereotactic body radiation therapy (SBRT) versus transarterial chemoembolization (TACE) with DEBDOX beads as a bridge to transplant in hepatocellular carcinoma (HCC). 2017 Gastrointestinal Cancer Symposium; San Fransisco, CA, USA, pp. 19-21, 2017.

34 Wahl DR, Stenmark MH, Tao Y, Pollom EL, Caoili EM, Lawrence TS, Schipper MJ and Feng M: Outcomes after stereotactic body radiotherapy or radiofrequency ablation for hepatocellular carcinoma. J Clin Oncol 34: 452-459, 2016.

35 Salama JK and Milano MT: Radical irradiation of extracranial oligometastases. J Clin Oncol 32: 2902-2912, 2014.

36 Park HC, Seong J, Han KH, Chon CY, Moon YM and Suh CO: Dose-response relationship in local radiotherapy for hepatocellular carcinoma. Int J Radiat Oncol Biol Phys 54: 150$155,2002$.

37 Goodman KA, Wiegner EA, Maturen KE, Zhang Z, Mo Q, Yang G, Gibbs IC, Fisher GA and Koong AC: Dose-escalation study of single-fraction stereotactic body radiotherapy for liver malignancies. Int J Radiat Oncol Biol Phys 78: 486-493, 2010.

38 Hall EJ and Giaccia AJ: Radiobiology for the radiologist. 7th ed. Williams \& Wilkins, Philadelphia, Lippincott, USA, 2011.

39 Jang WI, Kim MS, Bae SH, Cho CK, Yoo HJ, Seo YS, Kang JK, Kim SY, Lee DH, Han CJ, Kim J, Park SC, Kim SB, Cho EH and Kim YH: High-dose stereotactic body radiotherapy correlates increased local control and overall survival in patients with inoperable hepatocellular carcinoma. Radiat Oncol 8: 250, 2013.

40 Doi H, Shiomi H, Masai N, Tatsumi D, Igura T, Imai Y and Oh RJ: Threshold doses and prediction of visually apparent liver dysfunction after stereotactic body radiation therapy in cirrhotic and normal livers using magnetic resonance imaging. J Radiat Res 57: 294-300, 2016.

41 Doi H, Masai N, Uemoto K, Suzuki O, Shiomi H, Tatsumi D and Oh RJ: Validation of the liver mean dose in terms of the biological effective dose for the prevention of radiation-induced liver damage. Rep Pract Oncol Radiother 22: 303-309, 2017. 
42 Binkley MS, Trakul N, Jacobs LR, von Eyben R, Le QT, Maxim PG, Loo BW Jr, Shultz DB and Diehn M: Colorectal histology is associated with an increased risk of local failure in lung metastases treated with stereotactic ablative radiation therapy. Int J Radiat Oncol Biol Phys 92: 1044-1052, 2015.

43 Ahmed KA, Caudell JJ, El-Haddad G, Berglund AE, Welsh EA, Yue B, Hoffe SE, Naghavi AO, Abuodeh YA, Frakes JM, Eschrich SA and Torres-Roca: Radiosensitivity differences between liver metastases based on primary histology suggest implications for clinical outcomes after stereotactic body radiation therapy. Int J Radiat Oncol Biol Phys 95: 1399-1404, 2016.

44 Jingu K, Matsuo Y, Onishi H, Yamamoto T, Aoki M, Murakami Y, Yamashita H, Kakuhara H, Nemoto K, Sakayauchi T, Okamoto M, Niibe Y, Nagata Y and Ogawa K: Dose escalation improves outcome in stereotactic body radiotherapy for pulmonary oligometastases from colorectal cancer. Anticancer Res 37: 2709-2713, 2017.

45 Cox JD, Stetz J and Pajak TF: Toxicity criteria of the Radiation Therapy Oncology Group (RTOG) and the European Organization for Research and Treatment of Cancer (EORTC). Int J Radiat Oncol Biol Phys 31: 1341-1346, 1995.

46 Xu ZY, Liang SX, Zhu J, Zhu XD, Zhao JD, Lu HJ, Yang YL, Chen L, Wang AY, Fu XL and Jiang GL: Prediction of radiationinduced liver disease by Lyman normal-tissue complication probability model in three-dimensional conformal radiation therapy for primary liver carcinoma. Int J Radiat Oncol Biol Phys 65: 189-195, 2006.

47 Kim JH, Park JW, Kim TH, Koh DW, Lee WJ and Kim CM: Hepatitis $\mathrm{B}$ virus reactivation after three-dimensional conformal radiotherapy in patients with hepatitis B virus-related hepatocellular carcinoma. Int J Radiat Oncol Biol Phys 69: 813-819, 2007.

48 Ingold JA, Reed GB, Kaplan HS and Bagshaw MA: Radiation hepatitis. Am J Roentgenol Radium Ther Nucl Med 93: 200-208, 1965.

49 Dawson LA, Ten Haken RK and Lawrence TS: Partial irradiation of the liver. Semin Radiat Oncol 11: 240-246, 2001.

50 Withers HR, Taylor JM and Maciejewski B: Treatment volume and tissue tolerance. Int J Radiat Oncol Biol Phy 14: 751-759, 1988.

51 Schefter TE, Kavanagh BD, Timmerman RD, Cardenes HR, Baron A and Gaspar LE: A phase I trial of stereotactic body radiation therapy (SBRT) for liver metastases. Int J Radiat Oncol Biol Phys 62: 1371-1378, 2005.

52 Olsen CC, Welsh J, Kavanagh BD, Franklin W, McCarter M, Cardenes HR, Gaspar LE and Schefter TE: Microscopic and macroscopic tumor and parenchymal effects of liver stereotactic body radiotherapy. Int J Radiat Oncol Biol Phys 73: 1414-1424, 2009

53 Sanuki N, Takeda A, Oku Y, Eriguchi T, Nishimura S, Aoki Y, Mizuno T, Iwabuchi S and Kunieda E: Threshold doses for focal liver reaction after stereotactic ablative body radiation therapy for small hepatocellular carcinoma depend on liver function: evaluation on magnetic resonance imaging with Gd-EOB-DTPA. Int J Radiat Oncol Biol Phys 88: 306-311, 2014.

54 Kim TH, Kim DY, Park JW, Kim SH, Choi JI, Kim HB, Lee WJ, Park SJ, Hong EK and Kim CM: Dose-volumetric parameters predicting radiation-induced hepatic toxicity in unresectable hepatocellular carcinoma patients treated with three-dimensional conformal radiotherapy. Int J Radiat Oncol Biol Phys 67: 225$231,2007$.
55 Toramatsu C, Katoh N, Shimizu S, Nihongi H, Matsuura T, Takao S, Miyamoto N, Suzuki R, Sutherland K, Kinoshita R, Onimaru R, Ishikawa M, Umegaki $\mathrm{K}$ and Shirato $\mathrm{H}$ : What is the appropriate size criterion for proton radiotherapy for hepatocellular carcinoma? A dosimetric comparison of spotscanning proton therapy versus intensity-modulated radiation therapy. Radiat Oncol 8: 48, 2013.

56 Mizumoto M, Oshiro Y and Okumura T, Fukumitsu N, Numajiri H, Ohnishi K, Aihara T, Ishikawa H, Tsuboi K and Sakurai H: Proton beam therapy for hepatocellular carcinoma: A review of the University of Tsukuba experience. Int J Particle Ther 2: 570578, 2016.

57 Høyer M, Roed H, Traberg Hansen A, Ohlhuis L, Petersen J, Nellemann H, Kiil Berthelsen A, Grau C, Aage Engelholm S and Von der Maase H: Phase II study on stereotactic body radiotherapy of colorectal metastases. Acta Oncol 45: 823-830, 2006.

58 Barney BM, Markovic SN, Laack NN, Miller RC, Sarkaria JN, Macdonald OK, Bauer HJ and Olivier KR: Increased bowel toxicity in patients treated with a vascular endothelial growth factor inhibitor (VEGFI) after stereotactic body radiation therapy (SBRT). Int J Radiat Oncol Biol Phys 87: 73-80, 2013.

59 Bae SH, Kim MS, Cho CK, Kang JK, Lee SY, Lee KN, Lee DH, Han CJ, Yang KY and Kim SB: Predictor of severe gastroduodenal toxicity after stereotactic body radiotherapy for abdominopelvic malignancies. Int J Radiat Oncol Biol Phys 84: e469-e474, 2012.

60 Kavanagh BD, Pan CC, Dawson LA, Das SK, Li XA, Ten Haken RK and Miften M: Radiation dose-volume effects in the stomach and small bowel. Int J Radiat Oncol Biol Phys 76: S101-S107, 2010.

61 Sanuki N, Takeda A and Kunieda E: Role of stereotactic body radiation therapy for hepatocellular carcinoma. World $\mathrm{J}$ Gastroenterol 20: 3100-3111, 2014.

62 Eriguchi T, Takeda A, Sanuki N, Oku Y, Aoki Y, Shigematsu N and Kunieda E: Acceptable toxicity after stereotactic body radiation therapy for liver tumors adjacent to the central biliary system. Int J Radiat Oncol Biol Phys 85: 1006-1011, 2013.

63 Osmundson EC, Wu Y, Luxton G, Bazan JG, Koong AC and Chang DT: Predictors of toxicity associated with stereotactic body radiation therapy to the central hepatobiliary tract. Int J Radiat Oncol Biol Phys 91: 986-994, 2015.

64 Shaffer JL, Osmundson EC, Visser BC, Longacre TA, Koong AC and Chang DT: Stereotactic body radiation therapy and central liver toxicity: A case report. Pract Radiat Oncol 5: 282-285, 2015.

65 Toesca DAS, Osmundson EC, Eyben RV, Shaffer JL, Lu P, Koong AC and Chang DT: Central liver toxicity after SBRT: An expanded analysis and predictive nomogram. Radiother Oncol 122: 130-136, 2017.

66 Brown JM, Carlson DJ and Brenner DJ: The tumor radiobiology of SRS and SBRT: are more than the 5 Rs involved? Int J Radiat Oncol Biol Phys 88: 254-262, 2014.

67 Shibamoto Y, Miyakawa A, Otsuka S and Iwata H: Radiobiology of hypofractionated stereotactic radiotherapy: what are the optimal fractionation schedules? J Radiat Res 57: i76-i82, 2016.

68 Nagata Y (ed.): Stereotactic Body Radiation Therapy: Principles and Practices, 1st ed. Tokyo, Springer, 2015.

69 Wang W, Feng X, Zhang T, Jin J, Wang S, Liu Y, Song Y, Liu $\mathrm{X}, \mathrm{Yu} \mathrm{Z}$ and $\mathrm{Li} \mathrm{Y}$ : Prospective evaluation of microscopic extension using whole-mount preparation in patients with hepatocellular carcinoma: Definition of clinical target volume for radiotherapy. Radiat Oncol 5: 73, 2010. 
70 Wang MH, Ji Y, Zeng ZC, Tang ZY, Fan J, Zhou J, Zeng MS, $\mathrm{Bi} \mathrm{AH}$ and Tan YS: Impact factors for microinvasion in patients with hepatocellular carcinoma: possible application to the definition of clinical tumor volume. Int J Radiat Oncol Biol Phys 76: 467-476, 2010.

71 Bi AH, Zeng ZC, Ji Y, Zeng HY, Xu C, Tang ZY, Fan J, Zhou J, Zeng MS and Tan YS: Impact factors for microinvasion in intrahepatic cholangiocarcinoma: a possible system for defining clinical target volume. Int J Radiat Oncol Biol Phys 78: 14271436, 2010

72 Qian Y, Zeng ZC, Ji Y and Xiao YO: Microinvasion of liver metastases from colorectal cancer: predictive factors and application for determining clinical target volume. Radiat Oncol 10: $125,2015$.

73 Le QT, Shirato H, Giaccia AJ and Koong AC: Emerging treatment paradigms in radiation oncology. Clin Cancer Res 21: 3393-3401, 2015.

74 Postow MA, Callahan MK, Barker CA, Yamada Y, Yuan J, Kitano S, Mu Z, Rasalan T, Adamow M, Ritter E, Sedrak C, Jungbluth AA, Chua R, Yang AS, Roman RA, Rosner S, Benson B, Allison JP, Lesokhin AM, Gnjatic S and Wolchok JD: Immunologic correlates of the abscopal effect in a patient with melanoma. N Engl J Med 366: 925-931, 2012.

75 Hiniker SM, Chen DS, Reddy S, Chang DT, Jones JC, Mollick JA, Swetter SM and Knox SJ: A Systemic complete response of metastatic melanoma to local radiation and immunotherapy. Transl Oncol 5: 404-407, 2012.

76 Golden EB, Demaria S, Schiff PB, Chachoua A and Formenti SC: An abscopal response to radiation and ipilimumab in a patient with metastatic non-small cell lung cancer. Cancer Immunol Res 1: 365-372, 2013.
77 Hiniker SM, Reddy SA, Maecker HT, Subrahmanyam PB, Rosenberg-Hasson Y, Swetter SM, Saha S, Shura L and Knox SJ: A prospective clinical trial combining radiation therapy with systemic immunotherapy in metastatic melanoma. Int J Radiat Oncol Biol Phys 96: 578-588, 2016.

78 Marconi R, Strolin S, Bossi G and Strigari L: A meta-analysis of the abscopal effect in preclinical models: Is the biologically effective dose a relevant physical trigger? PLoS One 12: e0171559, 2017.

79 Wild AT, Herman JM, Dholakia AS, Moningi S, Lu Y, Rosati LM, Hacker-Prietz A, Assadi RK, Saeed AM, Pawlik TM, Jaffee EM, Laheru DA, Tran PT, Weiss MJ, Wolfgang CL, Ford E, Grossman SA, Ye X and Ellsworth SG: Lymphocyte-sparing effect of stereotactic body radiation therapy in patients with unresectable pancreatic cancer. Int J Radiat Oncol Biol Phys 94: 571-579, 2016.

80 Young KH, Baird JR, Savage T, Cottam B, Friedman D, Bambina S, Messenheimer DJ, Fox B, Newell P, Bahjat KS, Gough MJ and Crittenden MR: Optimizing timing of immunotherapy improves control of tumors by hypofractionated radiation therapy. PLoS One 11: e0157164, 2016.

81 Bang A, Wilhite TJ, Pike LRG, Cagney DN, Aizer AA, Taylor A, Spektor A, Krishnan M, Ott PA, Balboni TA, Hodi FS and Schoenfeld JD: Multicenter Evaluation of the tolerability of combined treatment with PD-1 and CTLA-4 immune checkpoint inhibitors and palliative radiation therapy. Int J Radiat Oncol Biol Phys 98: 344-351, 2017.

Received November 24, 2017

Revised December 15, 2017

Accepted December 18, 2017 